\title{
Sooting propensities of some gasoline surrogate fuels: combined effects of fuel blending and air vitiation
}

\author{
Muhammad Kashif ${ }^{a, b, c}$, Jérôme Bonnety ${ }^{a, b}$, Alexis Matynia ${ }^{a, b}$, Patrick Da \\ Costa $^{a, b}$, Guillaume Legros ${ }^{a, b, *}$ \\ ${ }^{a}$ Sorbonne Univ, UPMC Univ Paris 06, UMR 7190, Inst Jean Le Rond dAlembert, \\ F-75005, Paris, France. \\ ${ }^{b}$ CNRS, UMR 7190, Inst Jean Le Rond dAlembert, F-75005, Paris, France. \\ ${ }^{c}$ University of Central Punjab, Mechanical Department, Faculty of Engineering, 1 \\ Khayaban-e-Jinnah, Johar Town, Lahore, Pakistan.
}

\section{Abstract}

The sooting propensities of binary mixtures of n-heptane and toluene on one hand, and isooctane and toluene on the other hand are evaluated in atmospheric laminar diffusion flames. These hydrocarbons are indeed major components of any gasoline surrogate fuel. The sooting propensities are here measured in terms of Yield Sooting Indices (YSIs). To this end, twodimensional maps of soot volume fraction are extracted using Light Extinction Method (LEM) applied to methane diffusion flames doped with the vapors of the aforementioned mixtures. Burning in a coflowing oxidizer stream, these flames are established over the Santoro's axis-symmetric burner. The experimental setup allows the air stream to be diluted by carbon dioxide at a content normally encountered in internal combustion engines that use ex-

\footnotetext{
*Corresponding author

Email addresses: kashif091@gmail.com (Muhammad Kashif), jerome.bonnety@upmc.fr (Jérôme Bonnety), alexis.matynia@upmc.fr (Alexis Matynia), patrick.da_costa@upmc.fr (Patrick Da Costa), guillaume.legros@dalembert.upmc.fr (Guillaume Legros)
} 
haust gas recirculation (EGR). The evolution of the sooting propensity as a function of both toluene mole fraction in the binary mixtures and $\mathrm{CO}_{2}$ content of the air stream can then be revealed. The sooting tendencies of both kinds of blends decrease in a very linear way with increasing $\mathrm{CO}_{2}$ content of the air stream. On the opposite, the sooting tendencies of isooctane/toluene blends follow a strongly non-linear relationship with the toluene mole fraction due to synergistic effects while YSIs of n-heptane/toluene blends show very linear trends. Interestingly, these trends match those observed on other configurations of diffusion flames, further strengthening the consistency of the YSI methodology. The combined effects of fuel blending and $\mathrm{CO}_{2}$ dilution are also exhibited. All these trends can be of great importance for further investigations as toluene and isooctane mole fractions found in commercially available gasoline and gasoline surrogate fuels are prone to affect soot formation through a strong synergistic effect as identified in current study.

Keywords: gasoline surrogate fuels, yield sooting index, soot volume fraction maps

\section{Introduction}

Soot particles formed along combustion processes can be ultimately emitted into the atmosphere. Even at low concentration, the presence of these particles in urban air poses a serious public health problem [1, 2] and may play a critical role in global warming due to a significant capacity to absorb the incoming solar radiation [3]. Therefore, strategies aiming at the reduction of soot emission by combustion devices are required. 
While diesel engines exhibit some relatively high performances, especially in terms of $\mathrm{CO}_{2}$ specific emission $(\mathrm{g} / \mathrm{km})$ [4], they suffer from the acknowledged dilemma called $\mathrm{NO}_{\mathrm{x}}$-soot trade-off. Indeed, soot and $\mathrm{NO}_{\mathrm{x}}$ emissions cannot be reduced at the same time by the diesel combustion process itself. The technological solution currently implemented is to reduce $\mathrm{NO}_{\mathrm{x}}$ formation rate inside the cylinders. To this end, using exhaust gas recirculation (EGR) lowers combustion temperature and inhibits nitrogen chemistry [5]. In contrast, soot particles that form in the rich regions of the fuel spray experience a reduced oxidation rate due to the lower temperature but they can be captured and burnt downstream in the exhaust flow through a particulate filter. However, significant amounts of soot, especially ultra-fine particulate matters, can still escape from these soot traps [6]. Alternative technologies like Gasoline Direct Injection (GDI) have shown to increase combustion efficiencies exhibited by spark-ignited (SI) engines, therefore can help reduce $\mathrm{CO}_{2}$ specific emissions by these engines [7]. However, this kind of strategies also leads to the formation of rich region in the vicinity of the fuel spray, which in turn increases soot formation, therefore emission from gasoline engines. Due to these technological limitations, the strategies aiming at the reduction of soot emission by reciprocating engines need to be complemented by methodologies of fuel formulation $[8,9]$. The guidelines formulated by the recent Worldwide Fuel Charter [10] support these methodologies as the recommended aromatics content of gasoline has for instance been reduced from $50 \%$ down to $35 \%$ within few years.

Complex and competing physico-chemical processes are involved in soot formation during combustion [11]. The comprehensive understanding of in- 
ception, growth and subsequent oxidation of soot particles remains a hot issue, especially with respect to complex blends of hydrocarbons [3, 12]. More and more studies have focused on soot formation/oxidation for the last two decades, contributing to bridge the knowledge gap required to optimize fuel formulation $[3,13,14]$. Due to the recent development in computational power, refining the understanding of the aforementioned soot related processes can be achieved when contrasting experimental measurements with data extracted from numerical simulations of reference flames [5, 15]. This method then requires sophisticated computational and experimental tools.

At atmospheric conditions, many practical fuels are liquid mixtures of hundreds of hydrocarbons which have variable and coupled effects on regulated engine emissions and especially soot production [3, 9]. To develop a molecular-level understanding of soot formation/oxidation processes along combustion of these practical fuels, many works employ surrogate fuels and gradually increase the complexity of fuel formulation of these surrogates. Thus, special efforts have been devoted to the design of surrogate fuels for gasoline, diesel and jet fuels [16]. As an illustration of relevant surrogate fuels, blends of n-heptane, isooctane and toluene [16, 17] have been shown to fairly reproduce the combustion behavior of gasoline [18].

Among other characteristics, the propensity of a surrogate fuel to produce soot then needs to be assessed [14, 19]. To compare the sooting tendencies of a large number of chemical compounds, surrogate fuels, hydrocarbon based commercial fuels and mixture of hydrocarbons and bio-fuels, different methods like the smoke point height, the threshold sooting index (TSI), and the Yield sooting Index (YSI) are measured in laminar diffusion flames [20-24]. 
Among these protocols, the YSI methodology has lately been shown to be especially relevant and provide with fairly low uncertainties as the sooting propensity is then inferred directly from soot volume fraction measurements in the flame $[22,24]$. This sooting tendency is to be quantified in flames where the fuel to be investigated burns in homogeneous inflows. In this way, the discrimination among physical and chemical processes leading to soot formation in more practical devices will be allowed. The step that the determination of the fuel's YSI represents can then be considered a valuable contribution to the knowledge required to develop strategies for the reduction of the soot release by combustion devices.

Studying the sooting propensities exhibited by Primary Reference Fuels (PRFs), Kashif et al. [24] highlighted the blending effect that the evolution of YSI as a non-linear function of the isooctane mole fraction in the PRF reveals. Furthermore, these authors showed that a non-negligible cross effect of the isooctane mole fraction and $\mathrm{CO}_{2}$ dilution of air on YSI exists. Thus, linear-by-volume (lbv) models to estimate the combustion properties, such as YSI, of these simple bi-component fuels would give poor predictions. This behaviour is attributed to synergistic and antagonistic effects whose magnitudes depend not only on fuel blending but also on air vitiation.

These insights make the assessment of the combined effects of fuel blending and air vitiation crucial for surrogate fuels. Indeed, due to the relatively simple formulation of a surrogate fuel, the effect of fuel blending can be identified, therefore modeled. Moreover, investigating the effect of air vitiation by $\mathrm{CO}_{2}$ dilution is of practical relevance as $\mathrm{CO}_{2}$ is a major component of EGR. 
In the present study, the experimental methodology recommended by McEnally and Pfefferle is reproduced in order to measure the sooting tendencies of some gasoline surrogate fuels, i.e. binary mixtures of n-heptane/toluene and isooctane/toluene. Indeed, Yan et al. [25] noticed that for mixtures of n-octane and toluene, a parabolic curve fits the evolution of the experimental sooting tendencies with toluene mole fraction in the mixture (see Fig. 6 in Ref.25). Later studies then showed that blending toluene and isooctane also leads to that kind of non-linear effect $[17,19]$ while blends of toluene and n-heptane show fairly linear trends. In the following, the consistency of the YSI methodology is therefore assessed. The aforementioned blending effect is identified in terms of YSIs exhibited by n-heptane/toluene and isooctane/toluene mixtures. The methodology extended by Kashif et al. [24] to the sooting propensity in vitiated air is then applied. This enables the characterization of the combined effects of blending and $\mathrm{CO}_{2}$ dilution of air. Eventually, as a contribution to the experimental database that the current computational efforts request, the whole set of measured soot volume fraction fields measured in the reference flames established is delivered as a supplemental material.

\section{Quantification of sooting tendencies}

\subsection{Experimental methodology}

The experimental setup used to reproduce the methodology prescribed by McEnally and Pfefferle [23] has been carefully described in Ref.24. The diffu-

sion flames are established over an axis-symmetric coflow burner identical to the one described by Santoro et al. [26] and used in previous investigations 
$[24,27,28]$. In the following, the axis of symmetry is $(\mathrm{O} z)$ and its origin is located at the burner tip, defining the height above the burner (HAB). The cross-stream coordinate is $r$, which is the distance from the axis of symmetry.

In their original work [23], McEnally and Pfefferle suggested to evaluate the apparatus-independent Yield Sooting Index (YSI) of a fuel from the maximum soot volume fraction $f_{v, \max }=\max \left\{f_{v}\left(r, z_{\text {meas }}\right) \mid r \in[0, R]\right\}$ measured in the non-premixed flame burning in coflowing air. The fuel stream is composed of methane which is nitrogen diluted and doped at a given concentration with the vapor of the fuel whose sooting propensity is to be evaluated. In the original methodology, the measurement $f_{v, \max }$ is performed at a fixed height $z_{\text {meas }}$ above the burner. Then the fuel's YSI is calculated using Eq. (1):

$$
Y S I=C f_{v, \max }+D
$$

Here, C and D are apparatus-specific parameters that are determined by the arbitrary YSI values attributed to two reference fuels. For the present study, YSI values of benzene (30) and toluene (43.5 $\pm 3 \%$ ) reported by McEnally and Pfefferle [23] are used as references. YSI benzene is also the lower reference in the study of McEnally and Pfefferle [23]. YSI toluene is here chosen as the upper reference as it will be the sootiest fuel investigated along the present study. YSI $_{\text {toluene }}$ was delivered by McEnally and Pfefferle with an uncertainty of $3 \%$. The mean $\mathrm{YSI}_{\text {toluene }}$ is selected here which does not affect the interpretation of the results.

In the following, three similar methods provide with alternative evaluations of $f_{v, \max }$ that the two-dimensional fields of soot volume fraction allow. As prescribed by Kashif et al. [24], implementing these different 
methods enables the assessment of the YSI consistency. Thus, YSI Max.Ax.fv, $Y S I_{\text {Global Max.fv }}$ and $Y S I_{\text {Max.Int. fv }}$ are the measurements of the sooting propensity when $f_{v, \text { max }}$ is the maximum soot volume fraction on the flame axis, the peak soot volume fraction into the whole distribution, and the maximum value of the integrated soot volume $F_{v}(z)$, respectively. The latter distribution is given by the following expression:

$$
F_{v}(z)=\frac{1}{\pi R^{2}} \int_{0}^{R} 2 \pi r f_{v}(r, z) d r
$$

where $R=5.5 \mathrm{~mm}$ is the inner radius of fuel tube.

The Light Extinction Measurement (LEM) technique as implemented by Kashif et al. [27] provides with the two-dimensional soot volume fraction fields $f_{v}(r, z)$ required to evaluate the different kinds of $f_{v, \max }$ and input them in Eq. (1). To this end, the ray that outcomes from a $100 \mathrm{~mW}$ Continuous Wave laser operating at $645 \mathrm{~nm}$ is expanded to a collimated beam with a diameter of $70 \mathrm{~mm}$. After the beam crossed the flame, it is decollimated. A pinhole with a diameter of $800 \mu \mathrm{m} \pm 5 \mu \mathrm{m}$ is located at the focal point to provide a telecentric configuration possessing depth invariant magnification. The pinhole also allows the slight beam steering induced by the temperature gradient to be mitigated as this steering can bias the deconvolution process. The absorption of the beam through the flame is imaged by a Photon Focus MV1 12-bit progressive scan monochrome camera whose lens is equipped with a narrow band filter centered at $645 \mathrm{~nm}( \pm 2 \mathrm{~nm})$ and with a band width at one half the transmissivity maximum of $20 \mathrm{~nm}$. A digital pulse generator controls the occurrence and the duration of the camera's CMOS sensor exposure, together with the opening of a shutter that chops the laser source. A frame grabber records the frames captured by the camera on a 
computer. As a line-of-sight technique, LEM is combined with a subsequent deconvolution that incorporates a Tikhonov regularization [27]. The local extinction coefficient distribution $\kappa_{\lambda}^{e x t}(r, z)$ can then be computed from the projected data, i.e. the field of extinction coefficient integrated along the lineof-sight. This LEM technique has been shown to provide both fine temporal and spatial resolutions [27].

As prescribed by Zhou et al [29], the soot particles are here supposed to experience a relatively short residence time in the flame, therefore exhibit a range of diameter that is small enough to warrant the Rayleigh assumption. Thus, the local soot volume fraction is finally inferred from the local extinction coefficient as follows:

$$
f_{v}(r, z)=\lambda \kappa_{\lambda}^{e x t}(r, z) /\left(6 \pi\left(1+\alpha_{s a}\right) E(m)\right)
$$

where $E(m)$ is a function of the complex refractive index $m$ of soot. $\alpha_{s a}$ is the relative contribution of scattering to extinction, therefore is directly related to soot morphology.

Thus, a careful choice of the soot refraction index is crucial to the consistency of the methodology. While the values of $E(m)$ (about 0.28 at $645 \mathrm{~nm}$ ) reported by Krishnan et al [30] are almost identical for n-heptane, isooctane, toluene and benzene, a significant discrepancy of $\alpha_{s a}$ appears. In the following, the values of $\alpha_{s a}$ recommenced by Krishnan et al [30] are selected, i.e. 0 for n-heptane and isooctane, and 0.1 for benzene and toluene. This lead to values of the denominator in Eq. (3) equal to 5.3 for n-heptane and isooctane, and 5.8 for benzene and toluene. For binary mixtures of n-heptane/toluene and isooctane/toluene, $\alpha_{s a}$ is supposed to follow a linear dependency on the mole fraction of toluene in the blend. This adjustment is required to take 
into account the increasing fraction of light scattering in the phenomenon of light extinction by the soot particles when toluene mole fraction is increased. Indeed, with increasing toluene mole fraction, the particles exhibit higher characteristic diameters due to both hastened soot formation processes and longer residence time [30], as evidenced here (see section 3.1) by early soot load in the flame and increased flame length.

Nonetheless, $\alpha_{s a}$ stands in the denominator in Eq. (3). Accounting for the relative contribution of $\alpha_{s a}$ or not then induces discrepancies in YSI of the order of the experimental uncertainties. Finally, the aforementioned adjustment of $\alpha_{s a}$ hardly affects the calculated YSI values and the overall YSI trends.

\subsection{Procedure}

The procedure that is extensively documented in Ref.24 has also been followed along the present study. The reactants came from high-purity gas cylinders $\left(\mathrm{CH}_{4}\right.$ and $\mathrm{N}_{2} ; 99.9 \%$ stated purities), reagent-grade bottles (nheptane, isooctane and toluene; $99.5 \%$ ), and a compressor (air).

The only difference with the procedure reported in Ref.24 is the composition of the carrier gas which is now a mixture of methane (50\% in volume) and nitrogen ( $50 \%$ in volume), as opposed to pure methane used in the aforementioned study. The dilution of the carrier gas with nitrogen is here required to keep the sootier flames investigated below the smoke point conditions.

To evaluate the YSI of any blend stored in the tank of the setup, the carrier gas flow is first set through the Bronkhorst Controlled Evaporator and Mixer (CEM) and a lightly sooting diffusion flame of the carrier gas is 
established over the burner. Once the temperature of the CEM heater and the heated lines from the CEM to the burner is stabilized well above the condensation temperature of the liquid blend vapor, the liquid blend flowing from the tank through a Coriolis mass flow controller is vaporized. Its vapor is injected into the carrier gas. The flame then becomes brighter as soot production is clearly enhanced. A $10 \mathrm{~s}$ long sequence of LEM is recorded every minute at a frame rate of $30 \mathrm{~Hz}$ and with an exposure time of $15 \mathrm{~ms}$, showing that any raw extinction field exhibits a fluctuation of its peak lower than $5 \%$ over 10 minutes after the liquid flow was established. After the last recording, the liquid flow rate is set to zero. The flame then progressively turns blue, showing that for any condition the fuel stream is only composed of the carrier gas, one minute after the liquid flow rate is set to zero. The carrier gas flow rate is also set to zero. Once the flame is extinguished, the liquid fuel tank is flushed and the whole line from the tank to the burner tip is purged with an inert gas, i.e. Argon, during 5 minutes to remove all the liquid and vapors from the system. The tank is then refilled with the following liquid blend to be investigated.

The experimental parameters that were kept constant along the present study are reported in Tab. 1, together with those set by McEnally and Pfefferle. The values 30 and 43.5 were here assigned to the YSIs of benzene and toluene, respectively. The temperature along the fuel line, i.e. $150{ }^{\circ} \mathrm{C}$, is similar as that set by McEnally and Pfefferle. The coflowing air flow rate, i.e. $60000 \mathrm{~cm}^{3} / \mathrm{min}$, is higher here as this level was required to produce stable flames within the whole range of conditions investigated. However, some experiments conducted with a fuel line temperature of $180{ }^{\circ} \mathrm{C}$ on one hand, 
and with a coflowing air flow rate of $80000 \mathrm{~cm}^{3} / \mathrm{min}$ on other hand, lead to YSI modifications lower than 0.5. Thus, the influence of these parameters is considered negligible as compared to the standard deviation among the YSIs provided by the different methods described earlier.

The parameters varied in the present study are:

- the composition of the bi-component blend, identified by the toluene mole fraction $X_{\text {Tol }}$. in the mixture of toluene and n-heptane or toluene and isooctane. This parameter is adjusted when mixing different quantities of n-heptane or isooctane with toluene before refilling the tank.

- the vapor mole fraction $X_{v a p, i}(i=1,2)$ into the fuel stream. This is controlled by the liquid flow rate through the Coriolis mass flow controller. The mass flow rate required to set a given $X_{\text {vap }, i}$ is calculated with $\pm 1 \%$ uncertainty from compiled liquid phase densities and species molecular weights [31].

- the carbon dioxide mole fraction in the oxidizer stream, referred as $X_{\mathrm{CO}_{2}}$. A mass flow controller allows the carbon dioxide flow rate to be adjusted. This flow is then mixed with the constant air flow rate to complement the oxidizer flow.

For every parameter, the range investigated within the frame of the present study is specified in Tab. 2, together with the corresponding estimated uncertainty.

The dopant concentrations investigated correspond to two reference benzene mass flow rates, i.e. $0.42 \mathrm{mg} / \mathrm{sec}(1.5 \mathrm{~g} / \mathrm{hr})$ and $0.56 \mathrm{mg} / \mathrm{sec}(2.0 \mathrm{~g} / \mathrm{hr})$, 
at room temperature. These flow rates correspond to the vapor mole fractions $X_{v a p, 1}=1.8610^{-2}$ and $X_{v a p, 2}=2.4710^{-2}$, respectively. The mass flow rate for a given liquid fuel to be investigated is then adjusted such that its vapor mole fraction is equal to $X_{\text {vap }, i}(\mathrm{i}=1,2)$, calculated with an absolute uncertainty of approximately $0.1 \%$ from compiled liquid phase densities and species molecular weights [31]. The reported uncertainties of the mass flow controller used for liquid mixtures are of the order of $0.1 \%$ of measured value. The uncertainties related to the use of compiled densities and molecular weight are conveyed into the YSI measurements as these quantities are required to compute the mass flow rates of the different mixtures.

In the following, any YSI reported is the mean value among the 150 evaluations allowed by the 150 fields of soot volume fraction measured for every set of conditions.

\section{Effects of fuel blending and air vitiation}

Both single effects, i.e. fuel blending on one hand, and air vitiation on the other hand, are first assessed. Combined effects are then addressed.

For every set of conditions investigated, the experimental database, i.e. every distribution of $f_{v}(r, z)$ in the whole flame, is delivered as a supplementary material.

\subsection{Effect of fuel blending}

Figure 1 exhibits the soot volume fraction fields measured in methane flames doped with the vapors of different blends of n-heptane/toluene and isooctane/toluene $\left(X_{v a p, 2}=2.4710^{-2}\right)$ for some toluene mole fractions $X_{\text {Tol. }}$. and three different $\mathrm{CO}_{2}$ contents of the oxidizer. Benzene's YSI value being 
one of two references selected, the soot volume fraction maps in diffusion flames doped with benzene vapor are also given. With the diagnostics settings fairly spanning the raw extinction coefficients within the linear response range of the CMOS sensor, the detection threshold of the methodology in terms of peak soot volume fraction is here evaluated at $0.15 \mathrm{ppm}$ [24].

For both kinds of binary mixtures and at any $\mathrm{CO}_{2}$ content of the oxidizer, the peak soot volume fraction in the doped methane diffusion flame increases monotonically with increasing toluene mole fraction in the blend. Indeed, with increasing toluene mole fraction, the $\mathrm{C} / \mathrm{H}$ ratio increases. Still, the soot formation rate is governed (at the first order) by the fuel $\mathrm{C} / \mathrm{H}$ ratio [32]. Furthermore, the addition of aromatic compounds hastens soot formation in flames [19]. Therefore, increasing toluene mole fraction in the fuel stream results in a higher peak soot volume fraction. This also leads to a longer flame since the total fuel consumption is delayed due to the relatively slow soot chemistry.

To further elucidate the effect of blending on soot formation, the evolution of the integrated soot volume fraction $F_{v}(z)$ in the doped flames is plotted against the height above the burner in Figs. 2 for both (a) n-heptane/toluene and (b) isooctane/toluene mixtures. The first trend which also reveals qualitatively in Figs. 1 is the upstream location of the first soot particles detected which shifts gradually further upstream in the flame with increasing toluene mole fraction at any $\mathrm{CO}_{2}$ content of the oxidizer. Concomitantly, the peak integrated soot volume fraction increases monotonically with the increasing amount of toluene into these blends while its location also shifts upstream. Increasing toluene mole fraction then leads to higher slopes of the increasing 
parts of the curves which indicates an increasing soot formation rate. This results in larger soot volume fractions at any given HAB. These trends are qualitatively in agreement with the available data delivered by both coflow [14] and counterflow [19] burners.

However, a discrepancy between both mixtures appears in the increase rate of sooting propensity with toluene mole fraction. As revealed in Fig. 2 (b), the peak soot volume fraction, therefore the soot formation rate, exhibited by the mixture of isooctane and toluene increase first rapidly with toluene mole fraction $\left(0 \leq X_{\text {Tol. }} \leq 0.4\right.$ at $\left.X_{\mathrm{CO}_{2}}=0 \%\right)$. Then this increase starts decaying $\left(X_{T o l} \geq 0.6\right.$ at $\left.X_{\mathrm{CO}_{2}}=0 \%\right)$. On the opposite, the increase exhibited by the mixture of n-heptane and toluene appears to be more uniform.

To further support these comments, YSIs are calculated following the three alternatives prescribed in section 2.1. Figure 3 exhibits the evolutions of YSI as functions of toluene mole fraction in the blends of n-heptane/toluene (blue dots) and isooctane/toluene (black dots) for the three $\mathrm{CO}_{2}$ contents of the oxidizer investigated. The YSI scale is defined by reference values of 30 and $43.5 \pm 3 \%$ which are attributed to benzene and toluene, respectively, for $X_{\mathrm{CO}_{2}}=0 \%$. For a matter of legibility, all mean experimental YSIs, delivered by the three alternatives at both vapor mole fractions investigated, are not discriminated. These evaluations have been shown to be self-consistent as they lead to very similar evolutions of YSIs [24]. Second-order polynomials decently fit these experimental measurements. The procedure to derive them is given in section 3.3. The solid lines shown in Fig. 3 represent the evolutions of these polynomials. For both mixtures of n-heptane/toluene 
and isooctane/toluene, YSI increases monotonically with increasing toluene mole fraction, following the tendency exhibited by the absolute measurements shown in Figs. 1 and 2. The aforementioned discrepancy in the increase rate of sooting propensity with toluene mole fraction also reveals in terms of YSI.

On one hand, an almost straight line can readily fit the calculated YSIs of the n-heptane/toluene mixture at $\mathrm{X}_{\mathrm{CO}_{2}}=0 \%$ with reasonable accuracy showing a linear evolution of this mixture's sooting propensity as a function of toluene mole fraction. This linear trend turns into a slightly non-linear one at higher $\mathrm{CO}_{2}$ contents of the oxidizer. Thus, the sooting propensity seems to be affected by a coupling between fuel blending and $\mathrm{CO}_{2}$ dilution effects. On the other hand, a parabolic curve fits more properly the evolution of YSI exhibited by the isooctane/toluene mixture. This non-linear evolution of the sooting tendency with increasing concentration of toluene mole fraction can be explained in the light of the chemical mechanisms responsible for the formation of soot precursors species, i.e. poly-aromatic hydrocarbons (PAHs). Indeed, a synergistic effect of blending on the evolution of sooting propensity (measured here as YSI) has already been unveiled for binary mixtures of isooctane and toluene [19, 25].

As shown in Fig. 33 in Ref.3, the pyrolysis of n-heptane produces mainly short chain alkenes -especially ethylene-while isooctane preferentially leads to longer chain alkenes (propene, butene, pentene, and hexene). These latter species then especially decompose to form propargyl radicals $\left(\mathrm{C}_{3} H_{3}\right)$ and vinylacetylene $\left(\mathrm{C}_{4} \mathrm{H}_{4}\right)$. As an illustration, among the reactions leading to the formation of the aforementioned radicals, the decomposition of propene $\left(C_{3} H_{6}\right)$ to propargyl radicals $\left(C_{3} H_{3}\right)$ via a series of $\mathrm{H}$-atom abstractions is 
considered the preferential kinetic pathway [3].

In addition, Choi et al. [19] resumed the important pathways leading to the formation of poly-aromatic hydrocarbons (PAHs) which are precursors of soot. The dominant reactions which lead to the formation of benzene $\mathrm{C}_{6} \mathrm{H}_{6}$ (A1) and naphthalene $\mathrm{C}_{10} \mathrm{H}_{8}$ (A2) from toluene $\mathrm{C}_{6} \mathrm{H}_{5} \mathrm{CH}_{3}$ are depicted as follows:

$$
\begin{array}{rll}
\mathrm{C}_{6} \mathrm{H}_{5} \mathrm{CH}_{3}+H & \rightleftharpoons A 1+\mathrm{CH}_{3} & {[3,34,35]} \\
A 1-\mathrm{CH}_{2}+\mathrm{C}_{3} H_{3} & \rightleftharpoons A 2+H_{2} & {[34]} \\
A 1-C_{6} H_{5}+C_{4} H_{4} & \rightleftharpoons A 2+H & {[35]}
\end{array}
$$

Thus at lower toluene mole fraction the relatively high production of $\mathrm{H}$ radicals by heavy hydrocarbons such as n-heptane or isooctane may boost benzene and naphthalene formation, resulting in an increased sooting tendency that would have been under-predicted by a simple linear-by-volume model. Further enhancing this effect, the higher concentrations of propargyl $\mathrm{C}_{3} \mathrm{H}_{3}$ radicals and vinylacetylene $\mathrm{C}_{4} \mathrm{H}_{4}$ especially produced along the decomposition of isooctane hastens naphthalene formation and its growth to heavier PAHs.

The influence of these pathways among the overall soot formation processes is then reduced at higher toluene mole fraction due to the relatively lower concentrations of species originated from the pyrolysis of isooctane, resulting in relatively lower concentrations of propargyl radicals and vinylacetylene. As a consequence, the synergistic effect of blending on soot formation weakens with increasing mole fraction of toluene in isooctane/toluene 
mixture.

\subsection{Effect of air vitiation}

The effect of $\mathrm{CO}_{2}$ dilution of the coflowing air stream reveals readily in Figs. 1. The trends match the observations already reported in the literature related to methane diffusion flames doped with vapors of liquid fuels established over the Santoro's burner [14, 24, 33]. The sooting propensity of doped flames with either pure liquid compounds or binary blends of these liquid compounds decreases monotonically with increasing carbon dioxide mole fraction $\mathrm{X}_{\mathrm{CO}_{2}}$ in the oxidizer stream. Concomitantly, the flame length increases as the soot zone in the flame is shifted downstream. This effect can also be observed in Figs. 2. At any toluene mole fraction, $\mathrm{CO}_{2}$ dilution of the coflowing oxidizer results in a substantial decrease in integrated peak soot volume fraction in these diffusion flames. The other significant impact of $\mathrm{CO}_{2}$ dilution is the downstream shift of the soot inception region, therefore of the integrated peak soot volume fraction, which results in longer flames.

As discussed in detail in Ref. 24, the addition of $\mathrm{CO}_{2}$ affects soot formation through three main paths, i.e., dilution, thermal, and chemical effects. In the region where soot formation dominates soot oxidation, these three effects accumulate to delay the soot inception process, which leads to the aforementioned shift. In the region where soot oxidation dominates soot formation, the third effect induces an opposite tendency to the first two as it hastens soot oxidation slightly. However, this third effect does not significantly appear.

The reaction $\mathrm{CO}_{2}+\mathrm{H} \rightarrow \mathrm{CO}+\mathrm{OH}$ [19] is primarily responsible for the chemical effects of $\mathrm{CO}_{2}$ addition. $\mathrm{OH}$ and $\mathrm{O}$ species attack soot precursors 
and delay soot nucleation. $O H$ radical is known to attack mature soot particles resulting in lower soot volume fractions. The consumption of $\mathrm{H}$ species near the burner tip might slightly reduce the formation of the first benzene rings from toluene. This might also delay soot nucleation. These postulates are supported by the results shown in Figs. 1 and available results in the literature [19].

\subsection{Combined effects}

As already mentioned in section 3.1, Figure 3 shows the monotonic and potentially non-linear trends of YSI exhibited by the binary mixtures investigated. Therefore, a model scaling the absolute YSI as a function of $X_{\text {Tol. }}$ and $X_{\mathrm{CO}_{2}}$ is likely to be relevant. It will provide with a quantitative model predicting single effects and combined effects of both parameters on the YSIs of the gasoline surrogate fuels investigated. This would be a valuable benchmark for the validation of CFD simulations together with a simple engineering tool. To this end, the second-order polynomial in Eq. (7) is expected to decently model the non-linearity that can be observed in Fig. 3:

$$
\begin{aligned}
Y S I & =a_{\text {Tol. }}\left(\frac{1-X_{\text {Tol. }}}{\Delta X_{\text {Tol. }}}\right)^{2}+a_{C O 2}\left(\frac{X_{C O_{2}}}{\Delta X_{C O_{2}}}\right)^{2} \\
& +a_{\text {Tol. } / C O 2}\left(\frac{1-X_{\text {Tol. }}}{\Delta X_{\text {Tol. }}}\right)\left(\frac{X_{C O_{2}}}{\Delta X_{C O_{2}}}\right) \\
& +b_{\text {Tol. }}\left(\frac{1-X_{\text {Tol. }}}{\Delta X_{\text {Tol. }}}\right)+b_{C O 2}\left(\frac{X_{C O_{2}}}{\Delta X_{C O_{2}}}\right) \\
& +c
\end{aligned}
$$

where the variables $X_{\text {Tol. }}$ and $X_{\mathrm{CO}_{2}}$ have been reduced by their respective 
ranges investigated, i.e. $\Delta X_{T o l .}=1$ and $\Delta X_{\mathrm{CO}_{2}}=0.06$, to equitably weight their fluctuation spans. As pure toluene $\left(X_{\text {Tol. }}=1\right)$ is the common fuel investigated within the range of conditions covered with both binary mixtures, the second-order polynomial is derived as a function of $1-X_{T o l}$. The coefficient $c$, set by the measurements for $X_{\text {Tol. }}=1$ and $X_{\mathrm{CO}_{2}}=0$, is then expected to be equal to the index of toluene $Y S I_{T o l}$. for both n-heptane/toluene and isooctane/toluene mixtures.

The coefficients in Eq. (7) are determined using a trust-region-reflective algorithm [36] implemented into the Matlab environment to minimize the least-squares between the results of Eq. (7) and the set of YSIs measured. The coefficients are reported in Tab. 3. In addition, a model such as the one expressed in Eq. (7) enables confidence intervals (CI) to be stated [24]. In Fig. 3, the red and green bands represent the $95 \%$ confidence intervals for blends of n-heptane/toluene and isooctane/toluene, respectively. Their lower and upper bounds are evaluated using Eq. (8):

$$
C I\left(X_{T o l .}, X_{\mathrm{CO}_{2}}\right)=\overline{Y S I}\left(X_{T o l}, X_{\mathrm{CO}_{2}}\right) \pm 1.96 \times \sigma_{\max }
$$

where $\overline{Y S I}$ is the mean value of the YSIs measured at a given set of conditions $\left(X_{T_{\text {oll. }},} X_{\mathrm{CO}_{2}}\right)$ that are averaged over the three alternatives for YSI evaluation and both $X_{v a p, i}$. While, $\sigma_{\max }$ is the maximum value among the standard deviations computed at every set of conditions $\left(X_{v a p, i}, X_{T o l .}, X_{\mathrm{CO}_{2}}\right)$ investigated. The interval $\pm 1.96 \times \sigma_{\max }$ represents $95 \%$ of the area under the standard distribution curve [37]. Indeed, the deviation of every value from this fit is considered a contribution to the uncertainty in the YSI measurement. Therefore, the confidence intervals reported in Fig. 3 represent the 
uncertainties of the YSIs as derived from Eq.(7).

Except the mixture of n-heptane/toluene at $X_{\mathrm{Tol}}=0.2$ and $X_{\mathrm{CO}_{2}}=3 \%$, all the measured YSIs fall inside the zone encompassed between the upper and lower bounds of the confidence intervals. Thus, the relevance of the fitting model expressed by Eq. (7) is assessed.

Figures 4 and 5 exhibit the surfaces resulting from Eq. (7) with the coefficients obtained for the mixtures of n-heptane/toluene and isooctane/toluene, respectively. A set of YSI isolines are shown. Practical use of this kind of representation could be relevant as it can provide with the information for the selection of a range of conditions in terms of fuel mixture $\left(X_{\text {Tol. }}\right)$ and $\mathrm{CO}_{2}$ dilution of air $\left(X_{\mathrm{CO}_{2}}\right)$ that would leave the amount of soot produced below a requested threshold.

For the blends of n-heptane/toluene, the major influence of the linear trends reveals as the isolines are quite straight in Fig. 4. This is evidenced by the relative magnitudes of the coefficients reported in Tab. 3: $\left|a_{\text {Tol. }} / b_{\text {Tol. }}\right|_{n-h e p t a n e}=0.56$ and $\left|a_{C O 2} / b_{C O 2}\right|_{n-h e p t a n e}=0.10$. Nonetheless, the non-linear dependency of YSI on $X_{\text {Tol. }}$ slightly grows as $X_{\mathrm{CO}_{2}}$ increases. This can also be observed in Fig. 4. The upper isolines shift towards the higher toluene mole fractions at a higher rate than the lower isolines when $\mathrm{X}_{\mathrm{CO}_{2}}$ increases. Indeed, $a_{\mathrm{Tol} . / \mathrm{CO} 2}$ and $b_{\mathrm{CO} 2}$ have opposite sign. Therefore, when $X_{\mathrm{CO}_{2}}$ increases, the cross term $\left(\frac{1-X_{T o l}}{\Delta X_{T o l .}}\right)\left(\frac{X_{\mathrm{CO}_{2}}}{\Delta X_{\mathrm{CO}_{2}}}\right)$ weakens the linear term to a significant extent as $\left|a_{T o l .} / C O 2 / b_{\text {Tol. }}\right|_{n-\text { heptane }}=0.27$.

For the blends of isooctane/toluene, the substantial influence of the nonlinear dependency on the blending parameter $X_{\text {Tol }}$. exhibits as some of the isolines are really curved in Fig. 5. This is also evidenced by the relative mag- 
nitudes of the coefficients reported in Tab. 3: $\left|a_{\text {Tol. }} / b_{\text {Tol. }}\right|_{\text {isooctane }}=23.2$ and $\left|a_{C O 2} / b C O 2\right|_{\text {isooctane }}=0.07$. The latter ratio shows that for the blends of isooctane/toluene, the dependency on the $\mathrm{CO}_{2}$ dilution of the air stream remains very linear. Like for for the blends of n-heptane/toluene, $a_{\mathrm{Tol} . / C O 2}$ and $b C O 2$ have opposite sign. Therefore, the cross term $\left(\frac{1-X_{T o l .}}{\Delta X_{T o l .}}\right)\left(\frac{X_{C_{2}}}{\Delta X_{C O_{2}}}\right)$ further weakens the linear term when $\mathrm{X}_{\mathrm{CO}_{2}}$ increases. However, this combined effect is much stronger in this case as the ratio of combined term and linear term is ten times the same ratio in case of n-heptane i.e. $\left|a_{T o l . / C O 2} / b_{\text {Tol. }}\right|_{\text {isooctane }}=$ 2.7 while $\left|a_{\text {Tol. } / \mathrm{CO} 2} / a_{\text {Tol. }}\right|_{\text {isooctane }}=0.12$.

\subsection{Discussion}

In the present study, no discernible synergistic effect on the sooting tendencies is revealed for blends of n-heptane/toluene while one exhibited for blends of isooctane/toluene. Interestingly, Kashif et al. [24] also observed no significant synergistic effect for blends of n-heptane/isooctane as the sooting tendencies of these blends showed strongly linear evolutions with isooctane mole fraction. This finding clearly highlights that the crucial -therefore controlling- role of aromatic hydrocarbons is very sensitive to the chemical composition of the fuel blend. It would also be prudent to remind here as already discussed in introduction that toluene makes up an important percentage of PAHs in gasoline and is commonly used to model PAH chemistry in gasoline surrogate fuels.

As already mentioned, similar single blending effects have been reported by Choi et al. [19] for binary mixtures of n-heptane/toluene and isooctane/toluene. Interestingly, these authors studied soot formation and oxidation flames $(\mathrm{SFO})$ in a counter-flow burner. These trends are quantitatively 
different from the ones exhibited in the present study as the synergistic effect shown by Choi et al. reveals at higher toluene mole fraction. This discrepancy might be attributed to the difference in hydrodynamical conditions. Observing the evolutions of the maximum Laser Induced Fluorescence (LIF) and Laser Induced Incandescence (LII) signals measured by Choi et al (see Figs. 4 and 9 in Ref.19), it can be postulated that the PAH precursor species which are at the very origin of this synergistic behavior are readily oxidized in the counter-flow configuration due to higher mixing rate with the oxidizing species.

This mitigates ring formation rates. In contrast, the PAH precursor species experience later oxidizing conditions in the co-flow configuration which increases ring formation rates. This difference especially exhibits at lower toluene mole fractions, then weakens at higher toluene mole fractions, i.e. when the additional amount of PAH precursor species produced by the decomposition of isooctane is decreased.

Although not quantitative, this similarity further extends the consistency of the YSI methodology on the Santoro's burner.

\section{Conclusions}

The sooting propensities of binary mixtures of n-heptane/toluene and isooctane/toluene were evaluated in terms of Yield Sooting Indices (YSIs) in doped methane diffusion flames under the influence of $\mathrm{CO}_{2}$ dilution of the air stream. YSIs were inferred from two-dimensional fields of soot volume fraction that a Laser Extinction Method probing the whole flame delivered.

While YSI increases in a quite linear way with toluene mole fraction in 
the blend of n-heptane/toluene, a synergistic blending effect revealed for the mixtures of isooctane/toluene. Indeed, the higher concentrations of propargyl radicals and vinylacetylene that are produced along the decomposition of isooctane hastens naphthalene formation and its growth to heavier PAHs. This results in a higher rate of the soot production increase with toluene mole fraction for the blends of isooctane/toluene. Interestingly, these behaviors exhibited here over the co-flow burner match those reported for both kinds of blends in a counter-flow burner. This similarity further extends the relevance of the YSI methodology on the Santoro's burner.

Following a regular trend, the sooting propensity of every blend investigated decreases monotonically with increasing carbon dioxide mole fraction in the air stream. However, the combination of fuel blending and $\mathrm{CO}_{2}$ dilution of air may result in synergistic effects. It especially contributes to emphasize the non-linear blending effect exhibited by the n-heptane/toluene blends at higher $\mathrm{CO}_{2}$ dilution levels.

A quadratic equation was set to decently reproduce these trends. Indeed, the prediction of the synergistic behavior can be crucial as most of the surrogate fuels used in numerical simulations and engine testing contain toluene mole fraction within the range where this effect is not negligible. Furthermore, this kind of approach could contribute to a careful methodology for the formulation of commercial gasoline.

Further efforts should now be dedicated to the measurement of temperature fields. These would provide significant insights into the understanding of the physical and chemical processes that lead to the aforementioned effects. 
[1] M. Patricia Sierra-Vargas, L. M. Teran, Respirology 17 (2012) 10311038.

[2] M.R. Heal, P. Kumar, R.M. Harrison, Chem. Soc. Rev. 41 (2012) 66066630.

[3] C.S. McEnally, L.D. Pfefferle, B. Atakan, K. Kohse-Höinghaus, Prog. Energy Combust. Sci. 32 (2006) 247-294.

[4] G. Fontaras, V. Franco, P. Dilara, G. Martini, U. Manfredi Sci. Total Environ. 468-469 (2014) 1034-1042.

[5] F. Liu, H. Guo, G.J. Smallwood, O.L. Gülder, Combust. Flame 125 (2001) 778-787.

[6] E. Cauda, S. Hernandez, D. Fino, G. Saracco, V. Specchia Environ. Sci. Technol. 40 (2006) 5532-5537.

[7] T.W. Chan, E. Meoche, J. Kubsh, R. Brezny Environ. Sci. Technol. 48 (2014) 6027-6034.

[8] S. Dooley, S.H. Won, J. Heyne, T.I. Farouk, Y. Ju, F.L. Dryer, K. Kumar, X. Hui, C.-J. Sung, H. Wang, M.A. Oehlschlaeger, V. Iyer, S. Iyer, T.A. Litzinger, R.J. Santoro, T. Malewicki, K. Brezinsky, Combust. Flame 159 (2012) 1444-1466.

[9] M. Ußner, F. Müller-Langer, Accredit. Qual. Assur. 14 (2009) 685-691.

[10] Worldwide Fuel Charter, ACEA, the Alliance of Automobile Manufacturers, EMA, JAMA, and OICA Fifth Edition (2013). 
[11] M. Frenklach, Phys. Chem. Chem. Phys. 4 (2002) 2028-2037.

[12] A. D’ Anna, Proc. Combust. Inst. 32 (2009) 593-613.

[13] M. Tran, D. Dunn-Rankin, T. Pham, Combust. Flame 159 (2012) 21812191.

[14] D. Witkowski, K. Kondo, G. Vishwanathan, D. Rothamer, C.R. Shaddix, Combust. Flame 160 (2013) 1129-1141.

[15] H. Guo, K.A. Thomson, G.J. Smallwood, Combust. Flame 156 (2009) $1135-1142$.

[16] W.J. Pitz, N.P. Cernansky, F.L. Dryer, F.N. Egolfopoulos, J.T. Farrell, D.G. Friend, H. Pitsch, SAE J-Automot. Eng. 175 (2007) 21.

[17] N. Morgan, A. Smallbone, A. Bhave, M. Kraft, R. Cracknell, G. Kalghatgi, Combust. Flame 157 (2010) 1122-1131.

[18] J.C.G. Andrea, T. Brink, G.T Kalghatgi, Combust. Flame 155 (2008) 696-712.

[19] B.C. Choi, S.K. Choi, S.H. Chung Energy Fuels 33 (2011) 609-616.

[20] K. Dotson, P. Sunderland, Z.G. Yuan, D. Urban, Fire Safety J. 46 (2011) $550-555$.

[21] H.F. Calcote, D.M. Manos, Combust. Flame 49 (1983) 289-304.

[22] C.S. McEnally, L.D. Pfefferle, Environ. Sci. Technol. 45 (2011) 24982503. 
[23] C.S. McEnally, L.D. Pfefferle, Combust. Flame 148 (2007) 210-222.

[24] M. Kashif, J. Bonnety, P. Guibert, G. Legros, Combust. Flame 161 (2014) 1575-1586.

[25] S. Yan, E.G. Eddings, A.B. Palotas, R.J. Pugmire, A.F. Sarofim Energy Fuels 19 (2005) 2408-2415.

[26] R.J. Santoro, H.G. Semerjian, R.A. Dobbins, Combust. Flame 51 (1983) 203-218.

[27] M. Kashif, J. Bonnety, P. Guibert, C. Morin, G. Legros, Opt. Express 20 (2012) 28742-28751.

[28] G. Legros, T. Gomez, M. Fessard, T. Gouache, T. Ader, P. Guibert, P. Sagaut, J. L. Torero, Proc. Combust. Instit. 33 (2011) 1095-1103.

[29] L. Zhou, N. Dam, M. Boot, L. de Goey, Combust. Flame 160 (2013) $2507-2516$.

[30] S. Krishnan, K. Lin, G. Faeth, J. Heat Transfer 122 (2000) 517-524.

[31] CRC Handbook of Chemistry and Physics, CRC Press, Cleveland, OH, 85th edition, 2004.

[32] I. Glassman, Symp. (Intl.) Combust. 22 (1989) 295-311.

[33] Y. Kobayashi, T. Furuhata, K. Amagai, M. Arai, Combust. Flame 154 (2008) 346-355.

[34] G. Blanquart, P. Pepiot-Desjardins, H. Pitsch, Combust. Flame 156 (2009) 588-607. 
[35] C. Marchal, J.-L. Delfau, C. Vovelle, G. Moréac, C. Mounaïm-Rousselle, F. Mauss, Proc. Combust. Instit. 32 (2009) 753-759.

[36] T.F. Coleman, Y.Y. Li, SIAM J. Optimiz. 6 (1996) 418-445.

[37] J.F. Kenney, E.S. Keeping, Confidence limits for the binomial parameter, Princeton, NJ, Van Nostrand, pt.1, 3rd edition, 1962. 


\section{List of Figures}

1 Soot volume fraction fields in methane diffusion flames doped with different blends of: (a) n-heptane/toluene; (b) isooctane/toluene. $X_{\mathrm{Tol}}$. and $\mathrm{X}_{\mathrm{CO}_{2}}$ represent the toluene mole fraction in the binary blends of liquid fuels and the carbon dioxide mole fraction in the air stream, respectively. The vapor mole fraction of the blend in the fuel stream is $X_{v a p, 2}=2.4710^{-2}$.

2 Evolutions of the integrated soot volume fraction $F_{v}(z)$ for different $\mathrm{CO}_{2}$ mole fractions $\left(X_{\mathrm{CO}_{2}}\right)$ in the air stream and for different mole fractions of toluene $\left(X_{\text {Tol. }}\right)$ in the binary blends of: (a) n-heptane/toluene; (b) isooctane/toluene. The vapor mole fraction of the blend in the fuel stream is $X_{v a p, 2}=2.47$

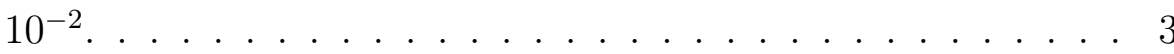

3 Yield Sooting Indices of binary mixtures of n-heptane/toluene (blue dots) and isooctane/toluene (black dots), from pure nheptane or pure isooctane $\left(X_{\text {Tol. }}=0\right)$ to pure toluene $\left(X_{\text {Tol. }}=1\right)$, and for different $\mathrm{CO}_{2}$ mole fractions in the air stream. Black solid lines are the interpolated YSI trends following Eq.(7). The shaded bands represent the $95 \%$ confidence intervals (CI).

4 Surface modeling the evolution of YSI as a function of toluene mole fraction $\left(X_{T o l .}\right)$ in the blend of $\mathrm{n}$-heptane/toluene and $\mathrm{CO}_{2}$ mole fraction $\left(\mathrm{X}_{\mathrm{CO}_{2}}\right)$ in the coflowing air. . . . . . . 36

5 Surface modeling the evolution of YSI as a function of toluene mole fraction $\left(X_{\text {Tol. }}\right)$ in the blend of isooctane/toluene and $\mathrm{CO}_{2}$ mole fraction $\left(\mathrm{X}_{\mathrm{CO}_{2}}\right)$ in the coflowing air. . . . . . . 37 
Table 1: Experimental parameters kept constant for the evaluation of YSIs.

\begin{tabular}{lll}
\hline Parameter & present study & McEnally and Pfefferle [22] \\
\hline Ambient Pressure $(\mathrm{atm})$ & 1.0 & 1.0 \\
Ambient Temperature $\left({ }^{\circ} \mathrm{C}\right)$ & 20 & 20 \\
Carrier gas Composition & $\mathrm{CH}_{4}(50 \%) \mathrm{N}_{2}(50 \%)$ & $\mathrm{CH}_{4}(55 \%), \mathrm{N}_{2}(45 \%)$ \\
Carrier gas flow rate $\left(\mathrm{cm}^{3} / \mathrm{min}\right)$ & $400 \pm 2.4$ at $20^{\circ} \mathrm{C}$ & 605 \\
Coflowing air flow rate $\left(\mathrm{cm}^{3} / \mathrm{min}\right)$ & $60000 \pm 360$ & 30000 \\
Evaporator temperature $\left({ }^{\circ} \mathrm{C}\right)$ & $150 \pm 1$ & N.A. \\
Heated line temperature $\left({ }^{\circ} \mathrm{C}\right)$ & $150 \pm 2$ & 145 \\
Reference YSIs & YSI(Benzene $)=30$ & YSI(Benzene $)=30$ \\
& YSI(toluene $)=43.5$ & YSI(dihydronaphthalene $)=100$ \\
\hline
\end{tabular}


Table 2: Experimental parameters varied for the evaluation of YSIs.

\begin{tabular}{llll}
\hline Parameter & & present study & $\begin{array}{l}\text { McEnally and Pfef- } \\
\text { ferle [22] }\end{array}$ \\
\hline$X_{\text {Tol. }}$ & range & {$[0,1]$} & $0 / 1$ \\
& step & 0.2 & N.A. \\
& uncertainty & $210^{-3}$ & N.A. \\
$X_{\text {vap }, i}$ & range & $X_{\text {vap }, 1}=1.8610^{-2}$ & $10^{-3}$ \\
& & $X_{v a p, 2}=2.4710^{-2}$ & \\
& step & - & N.A. \\
& uncertainty & $310^{-4}$ & $10^{-5}$ \\
$X_{C O_{2}}$ & range & {$[0,0.06]$} & N.A. \\
& step & 0.03 & N.A. \\
& uncertainty & $110^{-3}$ & N.A. \\
\hline
\end{tabular}


Table 3: Coefficients of the polynomial fitting the experimental YSIs (see Eq.(7)).

\begin{tabular}{lll}
\hline & n-heptane/toluene & isooctane/toluene \\
\hline$a_{\text {Tol. }}$ & -10.81 & -21.99 \\
$a_{C O 2}$ & 0.96 & 0.58 \\
$a_{\text {Tol. } / C O 2}$ & 5.27 & 2.56 \\
$b_{\text {Tol. }}$ & -19.48 & -0.95 \\
$b_{C O 2}$ & -9.22 & -8.75 \\
$c$ & 45.3 & 45.3 \\
\hline
\end{tabular}




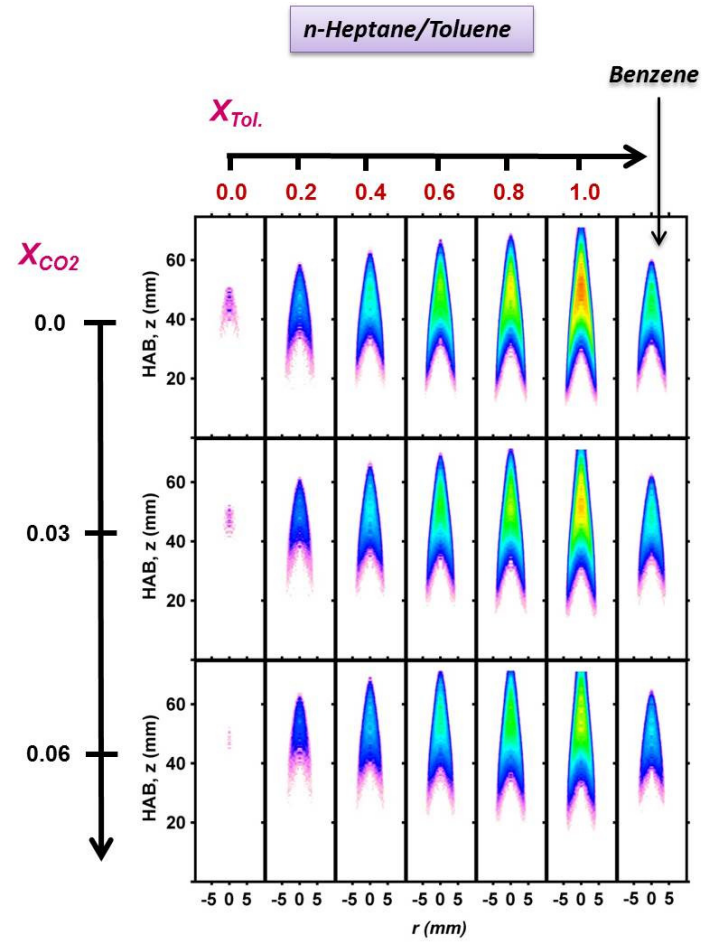

(a)

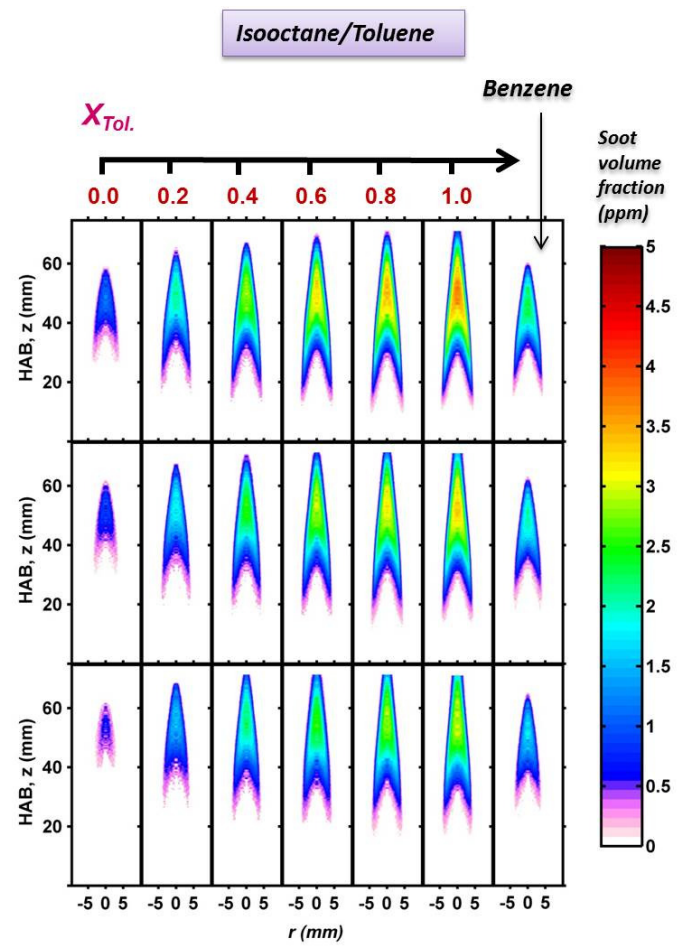

(b)

Figure 1: Soot volume fraction fields in methane diffusion flames doped with different blends of: (a) n-heptane/toluene; (b) isooctane/toluene. $X_{T o l}$. and $X_{\mathrm{CO}_{2}}$ represent the toluene mole fraction in the binary blends of liquid fuels and the carbon dioxide mole fraction in the air stream, respectively. The vapor mole fraction of the blend in the fuel stream is $X_{v a p, 2}=2.4710^{-2}$. 


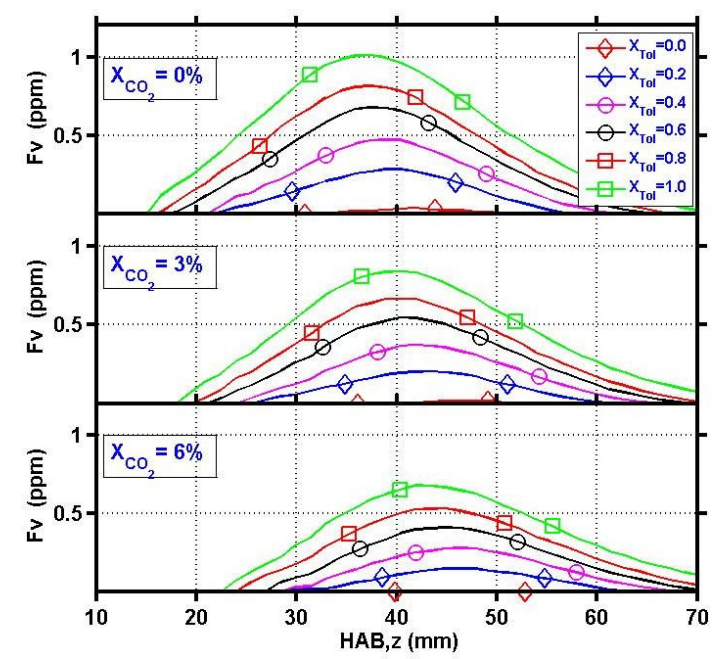

(a) n-heptane/toluene

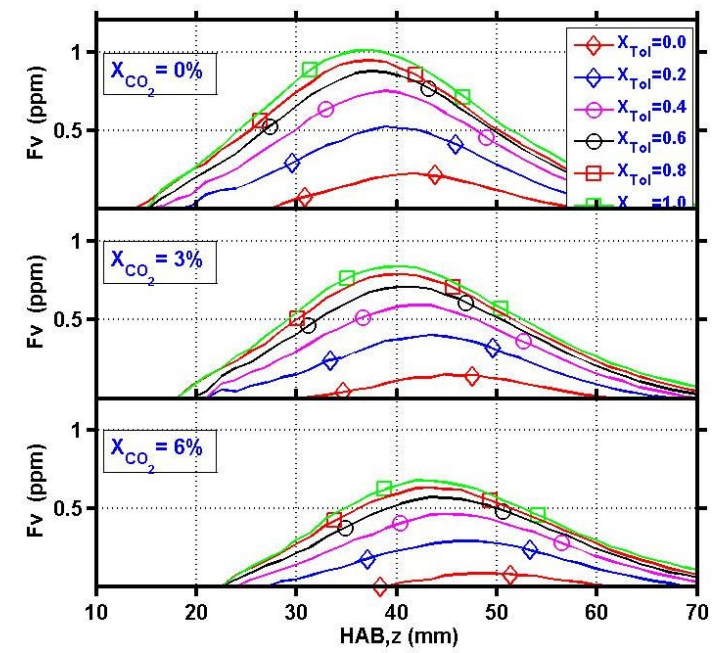

(b) isooctane/toluene

Figure 2: Evolutions of the integrated soot volume fraction $F_{v}(z)$ for different $\mathrm{CO}_{2}$ mole fractions $\left(X_{\mathrm{CO}_{2}}\right)$ in the air stream and for different mole fractions of toluene $\left(X_{\mathrm{Tol}}\right.$. $)$ in the binary blends of: (a) n-heptane/toluene; (b) isooctane/toluene. The vapor mole fraction of the blend in the fuel stream is $X_{v a p, 2}=2.4710^{-2}$. 


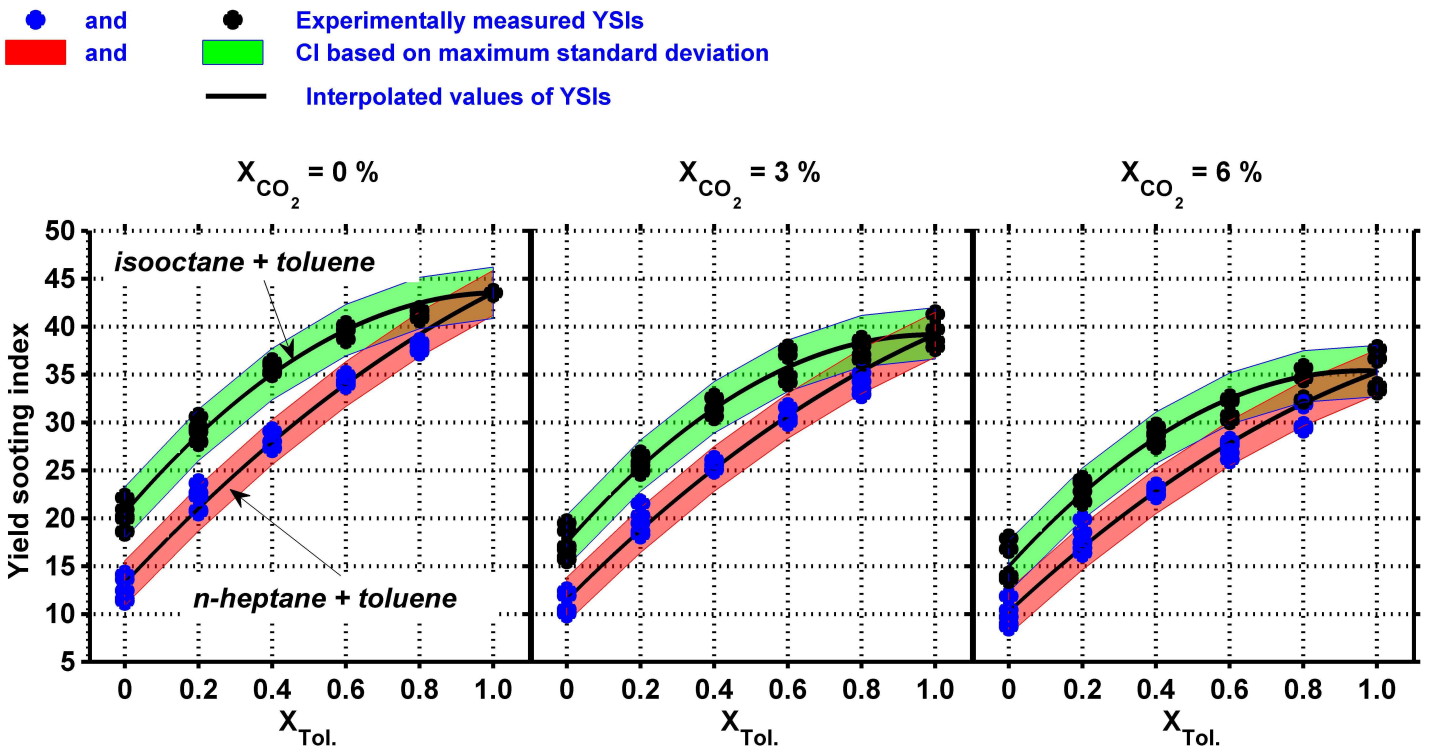

Figure 3: Yield Sooting Indices of binary mixtures of n-heptane/toluene (blue dots) and isooctane/toluene (black dots), from pure n-heptane or pure isooctane $\left(X_{\text {Tol. }}=0\right)$ to pure toluene $\left(X_{\text {Tol. }}=1\right)$, and for different $\mathrm{CO}_{2}$ mole fractions in the air stream. Black solid lines are the interpolated YSI trends following Eq.(7). The shaded bands represent the $95 \%$ confidence intervals (CI). 


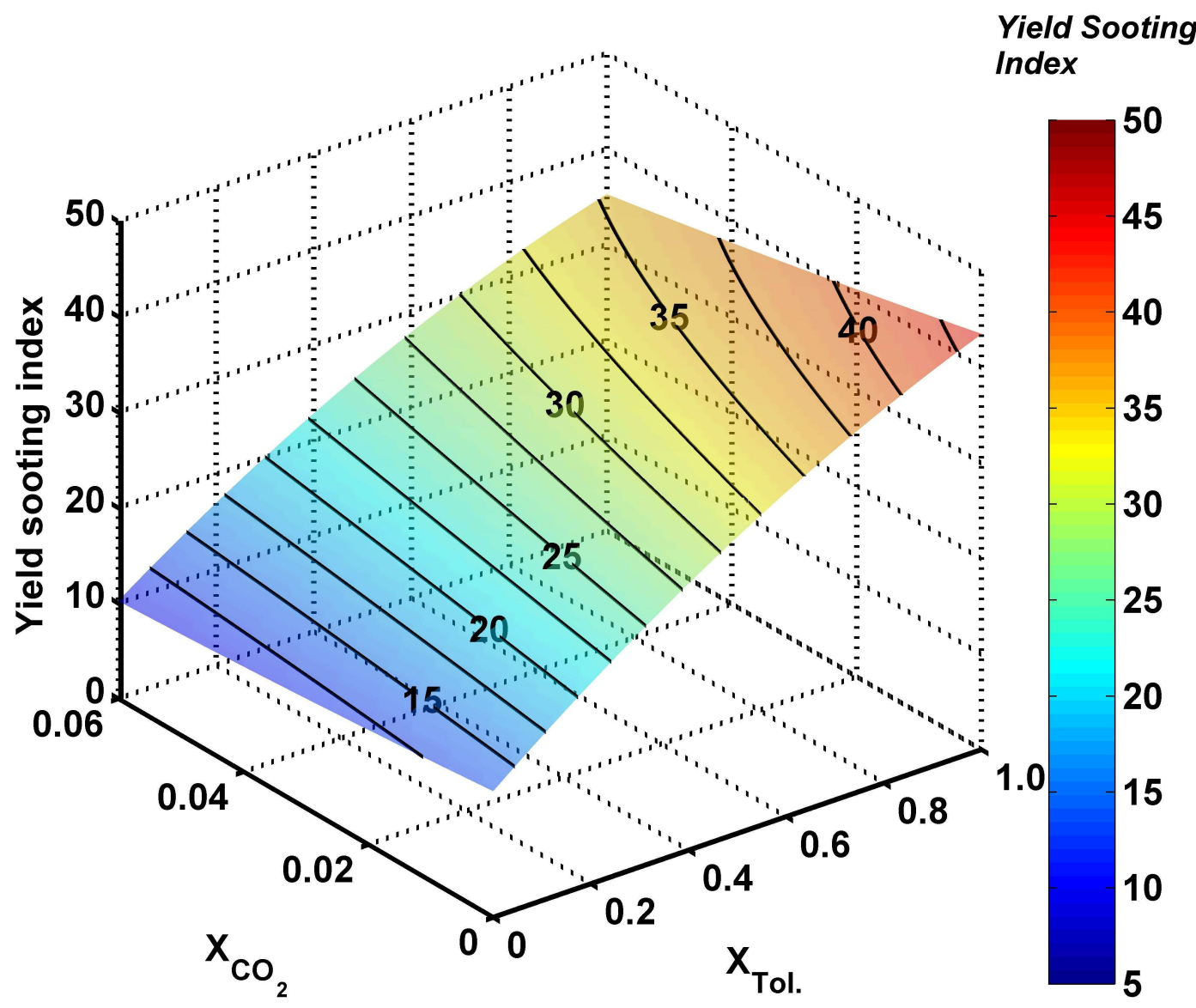

Figure 4: Surface modeling the evolution of YSI as a function of toluene mole fraction $\left(X_{T o l}.\right)$ in the blend of n-heptane/toluene and $\mathrm{CO}_{2}$ mole fraction $\left(\mathrm{X}_{\mathrm{CO}_{2}}\right)$ in the coflowing air. 


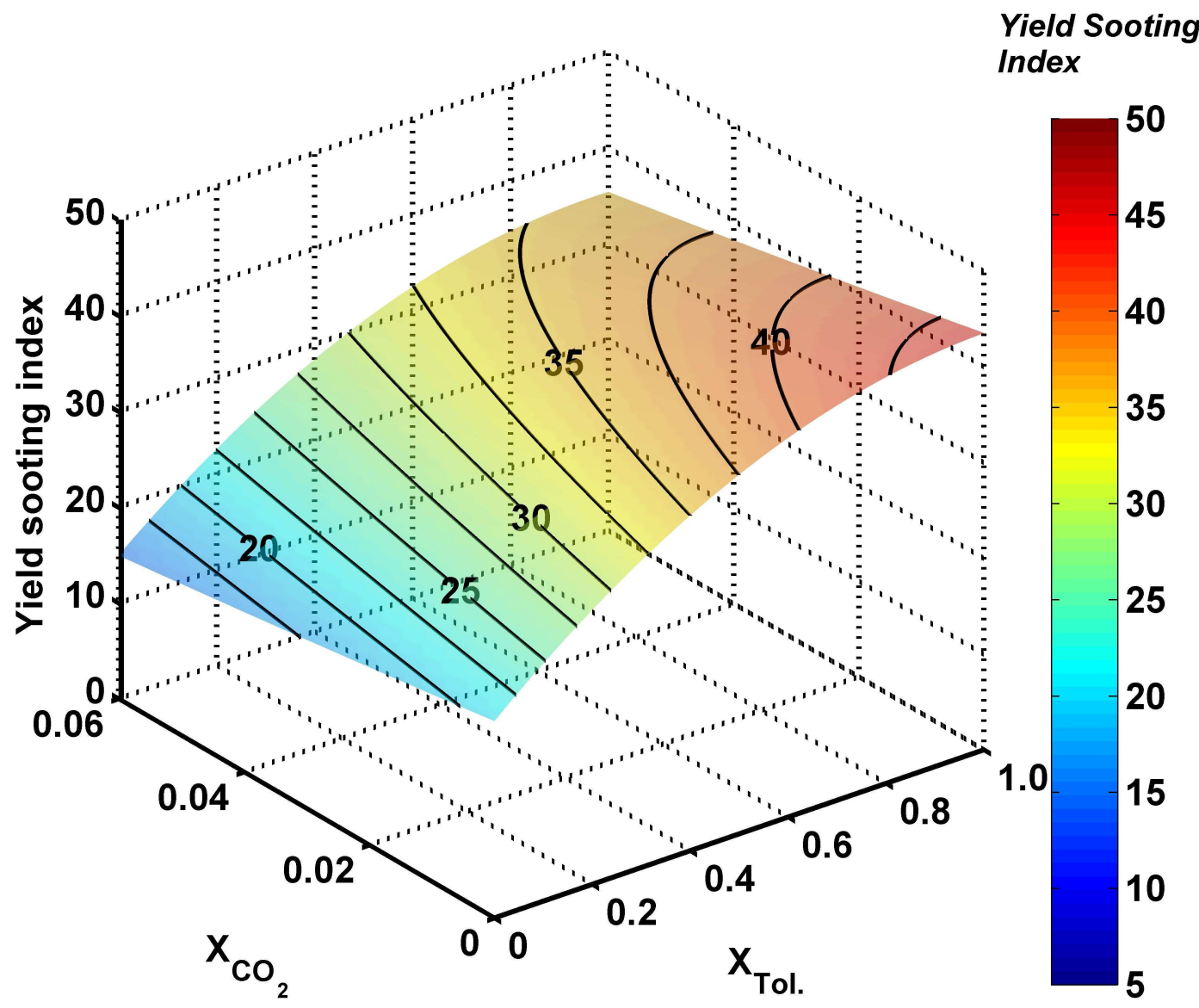

Figure 5: Surface modeling the evolution of YSI as a function of toluene mole fraction $\left(X_{T o l}.\right)$ in the blend of isooctane/toluene and $\mathrm{CO}_{2}$ mole fraction $\left(\mathrm{X}_{\mathrm{CO}_{2}}\right)$ in the coflowing air. 